\title{
Simultaneous observation of sporadic $E$ with a rapid-run ionosonde and VHF coherent backscatter radar
}

\author{
T. Maruyama ${ }^{1}$, S. Saito ${ }^{1}$, M. Yamamoto ${ }^{2}$, and S. Fukao ${ }^{2}$ \\ ${ }^{1}$ National Inst. of Information and Communications Technology, 2-1 Nukuikita 4-chome, Koganei, Tokyo, 184-8795 Japan \\ ${ }^{2}$ Research Institute for Sustainable Humanosphere, Kyoto University, Gokasho, Uji, Kyoto, 611-0011 Japan
}

Received: 29 December 2004 - Revised: 24 October 2005 - Accepted: 8 December 2005 - Published: 7 March 2006

\begin{abstract}
During the SEEK 2 rocket campaign, ionograms were recorded every minute at the Yamagawa Radio Observatory at about $90 \mathrm{~km}$ west of the region monitored by a VHF (very high frequency) coherent backscatter radar. Sporadic E-layer parameters, which include the critical (foEs) and blanketing (fbEs) frequencies, the layer height ( $\left.h^{\prime} E s\right)$, and the width of the range spread of sporadic E-traces, were compared with RTI (range-time-intensity) plots of VHF quasiperiodic $(\mathrm{QP})$ and continuous coherent backscatter echoes. A close relationship was found between the appearance of QP echoes in the RTI plots and the level of spatial inhomogeneity in sporadic E plasma, signified here by the difference between foEs and fbEs. During QP echo events, foEs increased while fbEs decreased, so that the difference foEs-fbEs was enhanced, indicating the development of strong spatial structuring in electron density within a sporadic E-layer. On the other hand, increases in sporadic $\mathrm{E}$ range spreading also correlated with the occurrence of QP echoes but the degree of correlation varied from event to event. Continuous radar echoes were observed in association with low altitude sporadic E-layers, located well below $100 \mathrm{~km}$ and at times as low as $90 \mathrm{~km}$. During the continuous echo events, both foEs and fbEs were less variable, and the difference foEs-fbEs was small and not as dynamic as in the QP echoes. On the other hand, the Es-layer spread intensified during continuous echoes, which means that some patchiness or corrugation in those low altitude layers is also necessary for the continuous backscatter echoes to take place.
\end{abstract}

Keywords. Ionosphere (Ionospheric irregularities; Midlatitude ionosphere) - Radio science (Ionospheric physics)

\section{Introduction}

VHF (Very High Frequency) backscatter from meter-scale sporadic E plasma irregularities is observed if the direction of the radar beam is perpendicular to the geomagnetic field.

Correspondence to: T. Maruyama

(tmaru@ nict.go.jp)
The resulting radar echoes usually exhibit an inclined striation pattern on a Range-Time-Intensity (RTI) plot. These have come to be known as quasi-periodic (QP) echoes (Yamamoto et al., 1991). The generation of scattering irregularities is believed to be associated with the gradient drift plasma instability, which requires the layer to have an inhomogeneous horizontal structure. Horizontal plasma structuring is also required for the generation of intense polarization electric fields (Haldoupis et al., 1996; Maruyama et al., 2000; Yokoyama et al., 2003, 2004), which are necessary for both gradient drift instability and/or two-stream instability.

There are a few reports on the relationship between the Eregion radar backscatter and Es parameters at mid-latitudes. Hussey et al. (1998) observed E-region irregularities using SESCAT, a 50-MHz coherent backscatter radar system, which is located in Crete, Greece, together with an ionosonde which was installed beneath the SESCAT scattering volume. They found significant correlations between backscatter power and Es characteristics, such as the top frequency of the layer, ftEs, and the apparent Es trace spread.

More recently, Ogawa et al. (2002) showed that the heights of the QP echoes obtained by the 46.5-MHz MU radar in Shigaraki, Japan, and the sporadic E-layer measured by an FMCW ionosonde in the viewing volume of the MU radar coincided. They also compared the appearance of QP echoes with ionosonde observations at Shigaraki, which was located about $130 \mathrm{~km}$ south of the MU radar viewing volume. QP radar echoes appearing before 02:00 LT were found to be enhanced when the difference between the critical (foEs) and blanketing (fbEs) frequencies was larger. The critical frequency denotes the maximum frequency of the Es echo trace on the ionogram, while the blanketing frequency denotes the minimum frequency of the $\mathrm{F}$ layer trace. Thus, radio waves at frequencies between fbEs and foEs are partially reflected by the sporadic E-layer and partially pass through it. The difference between the two frequencies signifies the degree of layer transparency. In the blob model of transparent sporadic $\mathrm{E}$, the highest and lowest electron densities within a horizontally stratified sporadic E-layer give the critical and blanketing frequencies, respectively. 


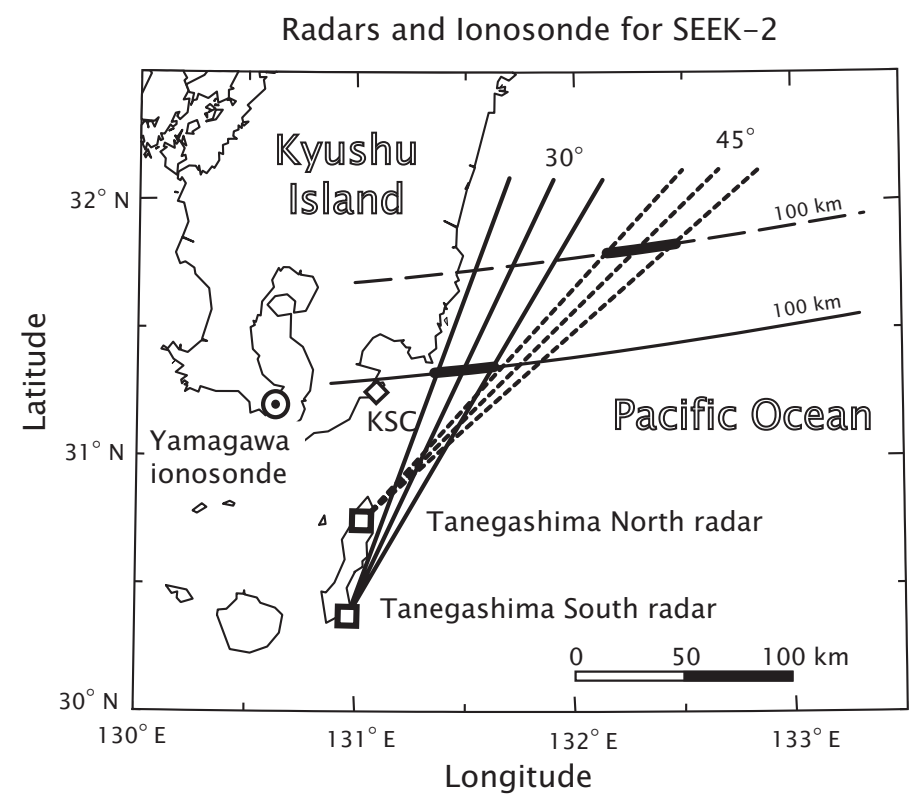

Fig. 1. Experimental setup showing the ionosonde and VHF radar locations and observing areas.

The significance of the difference between the foEs and fbEs in QP echo generation was discussed by Maruyama et al. (2000). They postulated a connection between the meter-scale irregularities responsible for the QP echo and the kilometer-scale plasma blobs responsible for the Fresnel diffraction of satellite radio beacon signals (Bowman, 1989; Maruyama 1995). Further, they attempted to observe radar backscatter and satellite radio signal fluctuations simultaneously using the MU radar and $150-\mathrm{MHz}$ radio signals transmitted from the Navy Navigation Satellite System (NNSS) orbiting satellites. On one occasion, plasma blobs producing Fresnel diffraction were found to coexist with small-scale irregularities that scattered the radar signal. A model calculation of the diffraction pattern indicated that the enhancement of the plasma concentration was consistent with the differences between foEs and fbEs as observed at Kokubunji, Tokyo, although the two locations were separated by about $300 \mathrm{~km}$.

This paper, which can be viewed as a continuation of previous studies, by Hussey et al. (1998) and Ogawa et al. (2002), explores the details of the relationship between the conditions prevailing inside sporadic E-layers and E-region backscatter at mid-latitudes. This was made possible by analyzing the variability of the Es parameters obtained with a rapid-run ionosonde during times of echo occurrences detected with a nearby VHF radar, during the SEEK-2 campaign (Yamamoto et al., 2005).

\section{Experiments}

SEEK-2 (Sporadic-E Experiment over Kyushu 2) refers to an observation campaign carried out in Japan in the summer of 2002, which was designed to study field-aligned irregularities in unstable sporadic E-layers by means of sounding rockets and ground-based observation facilities, including radars and optical instruments. The campaign and the various experiments are described in detail by Yamamoto et al. (2005). Two rockets were launched on the night of 3-4 August 2002, while most of the ground-based facilities were operated for several days before and after the launch. For this paper, VHF radar backscatter and ionosonde measurements, obtained for a period of about one month, were analyzed. The location of the radars and ionosonde are shown in Fig. 1.

Yamagawa $\left(130.62^{\circ} \mathrm{E}, 31.20^{\circ} \mathrm{N}\right)$ is one of four routine ionosonde stations operated by the National Institute of Information and Communications Technology (NICT). In accord with the SEEK-2 campaign, the ionosonde was operated in a rapid-run mode from 26 July to 31 August 2002, i.e. ionograms were obtained for every minute with a 15 -s sweep time from 1 to $30 \mathrm{MHz}$. The standard ionospheric parameters, including foEs and fbEs, were scaled manually for all the nights, whereas the range spread of sporadic E-trace was obtained for selected nights. Details on the ionosonde and the ionograms are given in the next section, along with some typical examples.

The backscatter observations were obtained with two VHF radars located near the north and south ends of Tanegashima. The radar beams were directed in a northeast direction, to intersect the magnetic field perpendicularly at sporadic E-layer heights. In this paper, we used data from the Tanegashima South radar because its viewing area was closer to the ionosonde station, as shown in Fig. 1. The Tanegashima South radar $\left(130.96^{\circ} \mathrm{E}, 30.38^{\circ} \mathrm{N}\right)$ is operated at $31.57 \mathrm{MHz}$, using a $16-$ bit complementary code with $20-\mathrm{kW}$ peak transmitter power. The antenna array consists of nine 


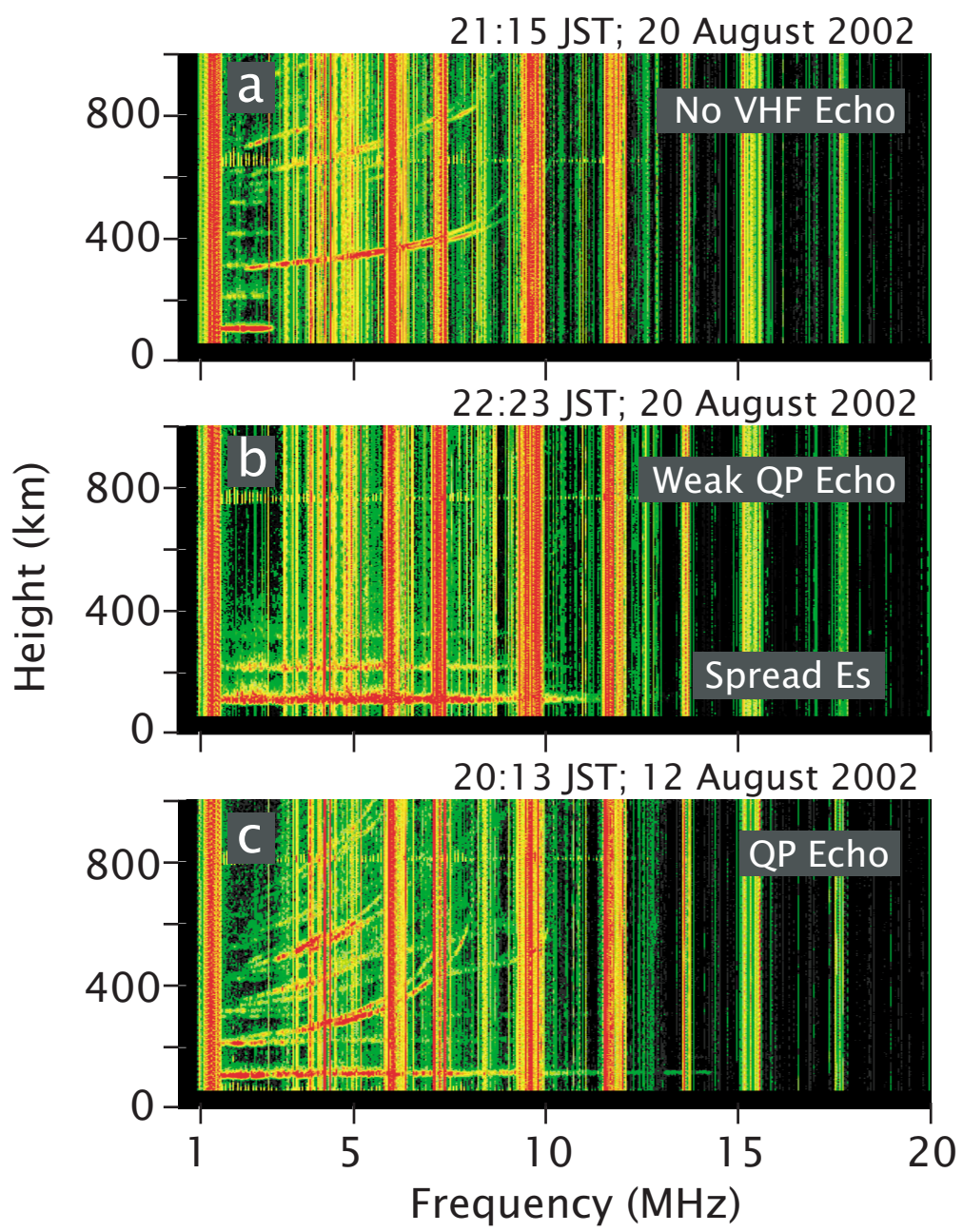

Fig. 2. Different types of ionograms showing a less developed Es trace which is not associated with QP echoes (a), fully blanketing and a spread Es trace associated with QP echoes (b), and a transparent, nearly spread Es trace associated with QP echoes (c).

Yagis forming a linear and triangular configuration, which provided a beam width of $10^{\circ}$, as shown in Fig. 1. In the figure, the two arcs represent the locus of the points at which the antenna beams intersect the geomagnetic field at right angles at $100 \mathrm{~km}$ for the Tanegashima North (long dashed line) and South (solid line) radars. For more details on the radars, see Saito et al. (2005).

The observation areas of the VHF radar and ionosonde were separated by about $90 \mathrm{~km}$ for the Tanegashima South radar and by about $200 \mathrm{~km}$ for the Tanegashima North radar. This separation of the observation areas requires a careful interpretation of the data, because it can introduce spatial differences if the echoing regions are localized. On the other hand, if the echo morphologies are similar at both locations, the ionospheric conditions producing the irregularities can be uniform over a wider area.

\section{Interpretation of the ionograms}

The ionosonde at Yamagawa is a simple conventional type with an $80-\mu$ s single pulse and a peak power of $10 \mathrm{~kW}$ using a crossed-delta antenna for both transmitting and receiving signals. The radiation pattern of the delta antenna was not measured, but it is expected to receive obliquely reflected signals because sufficiently intense signals are received and used to construct oblique ionograms between the other three ionosonde stations. The received signal was sampled with an 8-bit accuracy, without an Automatic Gain Control (AGC) function, every $2 \mathrm{~km}$ over the virtual height range from 60 to $1600 \mathrm{~km}$. The raw data were recorded without any noise reduction. Noise reduction could be applied in post processing, but in order to enable the analysis of weak signals, it was not used in this study. Examples of 8-bit color ionograms are shown in Fig. 2. Since the ionosonde had no directional finding capability, and the ordinary and extraordinary waves were not distinguished, there were occasional difficulties in the interpretation of the ionograms. 

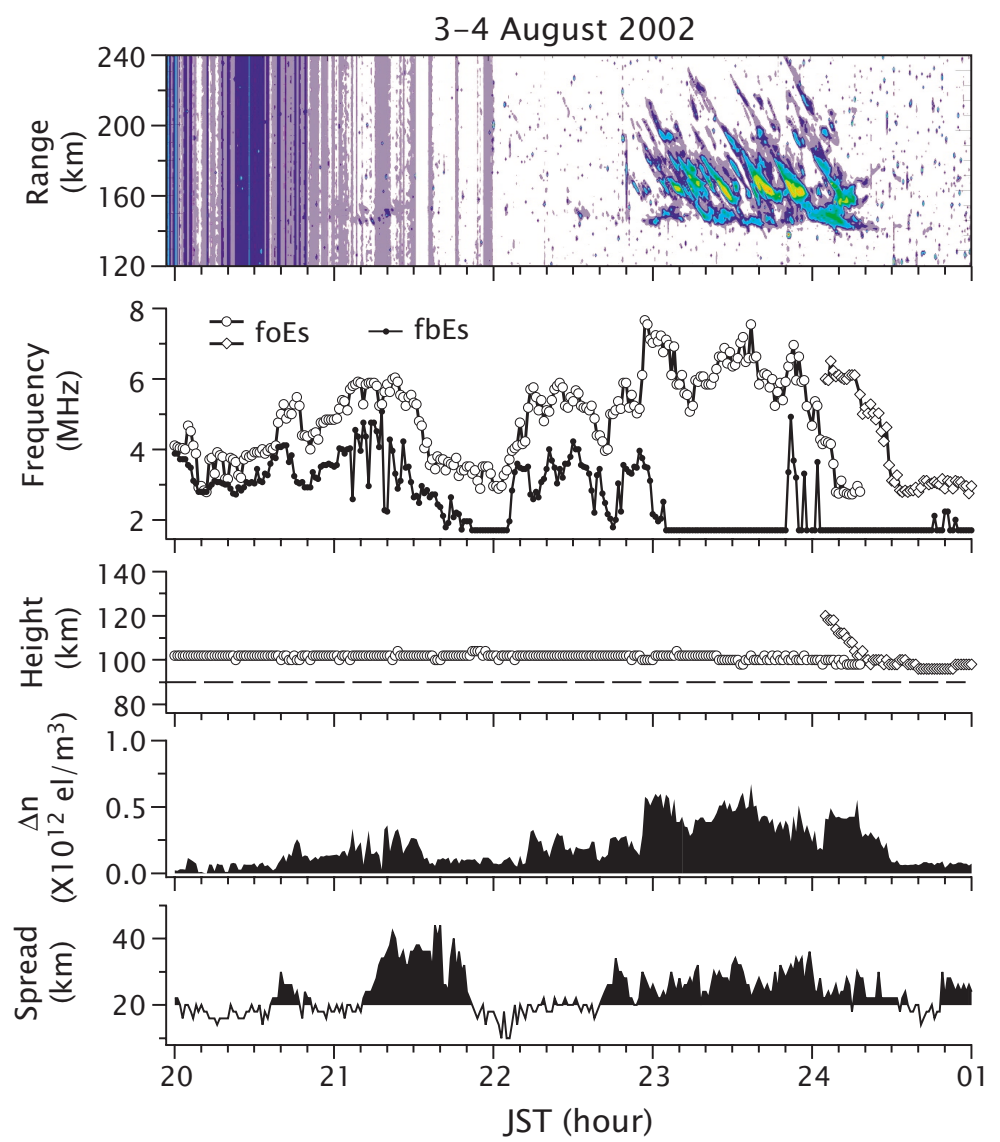

Fig. 3. Range-time-intensity map of Tanegashima South radar (top panel), critical and blanketing frequencies of sporadic E (second panel), virtual height of the sporadic $\mathrm{E}$ (third panel), inhomogeneity factor $\Delta \mathrm{n}$ (fourth panel), and range spread (bottom panel) for the event on the night of 3-4 August 2002.

Figure 2a shows a weak sporadic E-layer occurring at 21:15 JST on 20 August 2002, when no VHF radar echoes were observed. Note that the signals seen near $650 \mathrm{~km}$, and also at $750 \mathrm{~km}$ in the middle panel, as well as at 50 and $800 \mathrm{~km}$ in the bottom panel, were due to interference from an MF radar operating near the ionosonde. As seen, the top frequency of the Es-layer, $\mathrm{ftEs}$, is $2.84 \mathrm{MHz}$ and the blanketing frequency, fbEs, is $2.20 \mathrm{MHz}$. The difference between the $\mathrm{ftEs}$ and fbEs was $0.64 \mathrm{MHz}$, which was close to half the gyro frequency $\left(\mathrm{f}_{H}=1.22 \mathrm{MHz}\right)$. Thus, the ftEs was nearly equal to the extraordinary wave critical frequency fxEs. We considered the relation foEs $=\mathrm{ftEs}-\mathrm{f}_{H} / 2$ as being approximately valid, although there might be a difference between foEs and fxEs for transparent sporadic E (Whitehead, 1972) for which the above relationship is not always valid. Figure $2 \mathrm{~b}$ shows the ionogram obtained about one hour later (22:23 JST on 20 August 2002), in which an Es layer was highly developed and fully blanketing the F-layer (note that just before the full blanketing, foF 2 was about $9 \mathrm{MHz}$ ). At this time, and when the Es trace was strongly spread, a moderately strong QP echo was detected by the VHF radar. Figure $2 \mathrm{c}$ shows the ionogram obtained when an intense QP echo was detected at 20:13 JST on 12 August 2002. The critical frequency extended up to $14.5 \mathrm{MHz}$, while the blanketing frequency was around $2.0 \mathrm{MHz}$. The Es trace was slightly spread, and the echo strength weakened gradually with increasing frequency.

These examples show that both spread Es and transparent Es indicate the presence of inhomogeneity in the layer, but they do not quantify in the same manner the state of inhomogeneity. This is easily understood by considering a simple case of an undulated thin layer without any spatial changes in the maximum electron density. Such a layer could cause spread Es by oblique echoes from multiple reflection points, while vertically reflected F-layer echoes are blanketed below foEs, i.e. foEs $=$ fbEs. Actual sporadic E inhomogeneity must be a mixture of the blob and height undulation models.

\section{Results}

It is important to stress that VHF backscatter was always observed in the presence of a sporadic E-layer, a fact that is well known for mid-latitude E-layer backscatter. In the following, we present case studies for four typical nights. On the night of 3-4 August 2002, when the two rockets were launched, QP echoes were observed in close connection with 

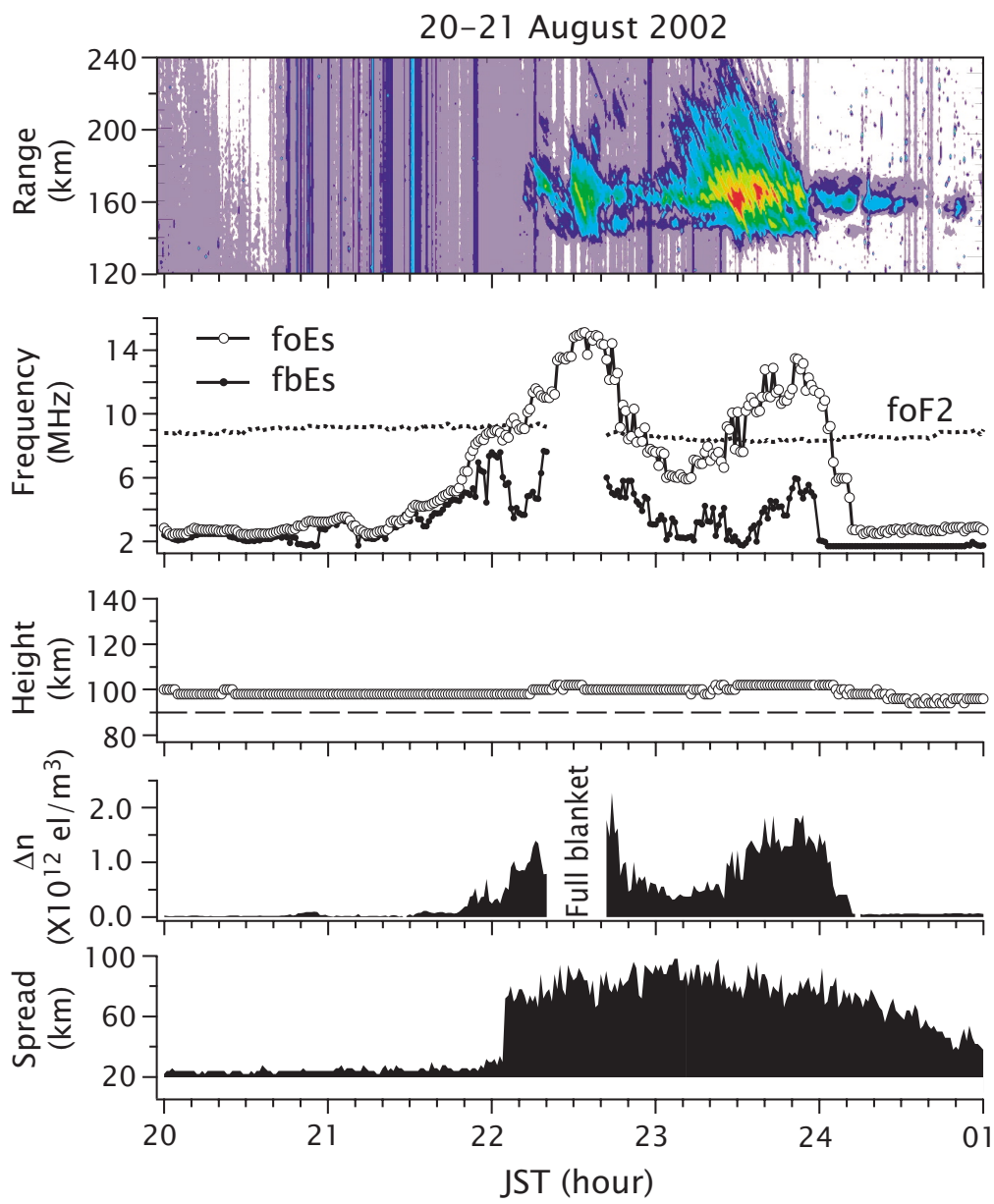

Fig. 4. Same as Fig. 3, but for the night of 20 to 21 August 2002.

transparent sporadic E-layers. On the night of 20-21 August very strong and fully blanketing sporadic $\mathrm{E}$ was associated with radar backscattering, while on the night of 8-9 August continuous echoes were detected. On the night of 19-20 August continuous echoes were followed by QP echoes.

\subsection{3-4 August 2002 (day of rocket launching)}

The results of the VHF radar and ionosonde observations are shown in Fig. 3 for the period from 20:00 JST, $3 \mathrm{Au}-$ gust to 01:00 JST, 4 August 2002. The RTI plot of the VHF radar echo in the top panel exhibited descending QP striations from 23:00 JST, 3 August to 00:20 JST, 4 August. Before the onset of the VHF radar echoes, both foEs and fbEs varied generally in a similar fashion, as shown in the second panel. However, near the time of the echo onset, foEs increased whereas fbEs decreased simultaneously. The increase in foEs was step-like, over the short period from 22:55 to 22:57 JST, while fbEs decreased gradually, compared with the change in foEs, and continued to decrease beyond the scaling limit of 1.7 MHz at 23:05 JST, below which intense $\mathrm{MF}$ radio transmission interference disrupted the observation (see Fig. 2). After midnight, the layer that had persisted for several hours rapidly weakened, while another faint layer appeared near $120 \mathrm{~km}$. The second layer apparently descended to the height of the first one and merged with it, as shown in the third panel. Such descending layers, which were often observed during the campaign period, will be discussed later.

The parameters that signify the layer roughness are shown in the bottom two panels. The fourth panel shows the electron density spatial inhomogeneity, $\Delta \mathrm{n}$, computed from the difference between the foEs and fbEs. For the case when fbEs drops below $1.7 \mathrm{MHz}$, the actual $\Delta \mathrm{n}$ must be larger than the plotted values. We note that the increase in $\Delta \mathrm{n}$ coincided with the appearance of the VHF radar echoes. The bottom panel shows the Es range spread. A meaningful threshold level for spread Es was empirically determined as $20 \mathrm{~km}$ by comparing individual ionograms. The narrowing of the trace near 22:00 JST was due to the weakening of the reflected signal strength. The portions above the threshold level are shaded. The most intense Es spread on this night was observed from $21: 10$ to $21: 50$ JST with a slightly weaker one from 22:40 to 00:20 JST. The latter period generally corresponded to the occurrence of radar backscattering, but the spread Es started about 20 min earlier than the radar echoes. This can be due to the spatial difference between the radar 

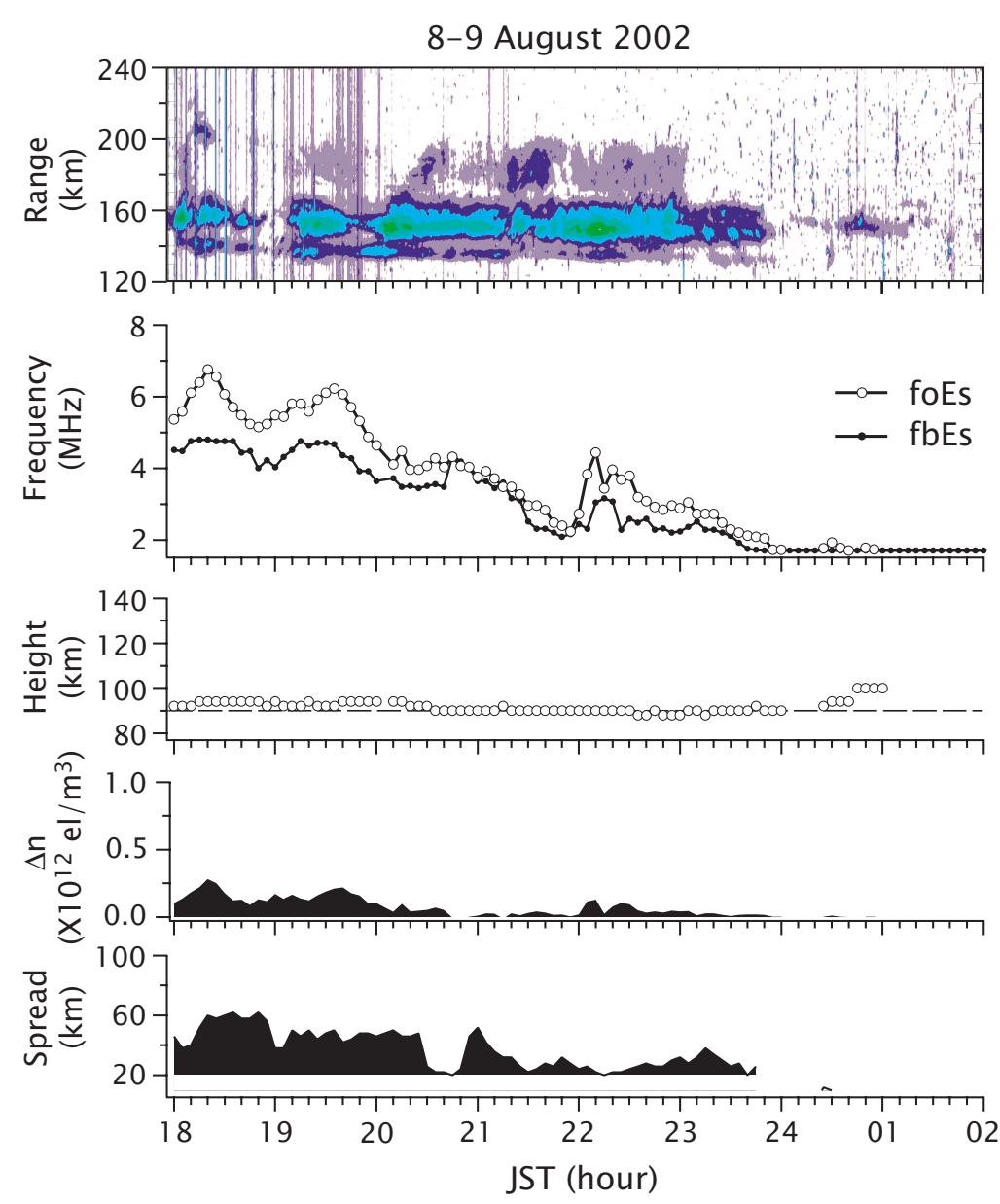

Fig. 5. Same as Fig. 3, but for the night of 8 to 9 August 2002. The radar echoes were of the continuous type.

scattering volume and the ionosonde. Very faint radar echoes were observed during the former period, despite the intense spread Es.

\subsection{0-21 August 2002}

Figure 4 shows an event on the night of 20-21 August 2002 in the same format as in Fig. 3. During this event, the sporadic $\mathrm{E}$ intensified during two time intervals, one around 22:35 JST and the other at 23:50 JST on 20 August (second panel). The maximum foEs reached $15 \mathrm{MHz}$, and the $\mathrm{F}$ layer trace was fully blanketed during the period from $22: 21$ to 22:41 JST. The VHF radar echoes also appeared at two time intervals in accord with the intensification of the sporadic $\mathrm{E}$ (top panel). However, the significance of the events during the two periods was reversed for the radar echo and sporadic E. The strongest radar echo was detected in the latter period, while the foEs was higher in the former period. The layer height (third panel) did not change significantly throughout the whole period.

The fourth panel shows $\Delta \mathrm{n}$ as derived from foEs and fbEs. Although $\Delta \mathrm{n}$ was not computed for the central part of the former period because of full blanketing, it appeared to correlate reasonably well, but not exactly, with the VHF echoes. During the second interval of echo occurrence, the variations in $\Delta \mathrm{n}$ appeared about $15 \mathrm{~min}$ later relative to those of the radar echoes.

The bottom panel shows the layer spread. Almost in accord with the development of sporadic E and the increase in $\Delta \mathrm{n}$, Es spread started to increase after 22:00 JST. This spread was quite severe compared with the event on 3-4 August in Fig. 3. (Note that the vertical axis scale is doubled in Fig. 4.) Despite the temporal variation in foEs and fbEs, Es spread was persistently strong and continued even after the period when foEs dropped significantly at 00:10 JST on 21 August. The temporal variability in Es spread did not appear to follow the variability seen in VHF radar echo intensity.

\subsection{8-9 August 2002 (continuous echo)}

Figure 5 shows another type of radar backscatter event, in which no clear structure was observed in the RTI plot, in contrast with the three examples shown previously. The near-range continuous echoes at $140 \mathrm{~km}$ and the far-range ones at $180 \mathrm{~km}$ were most likely detected by the radar's side lobe beams (Saito et al., 2005). Note that, in this case, 


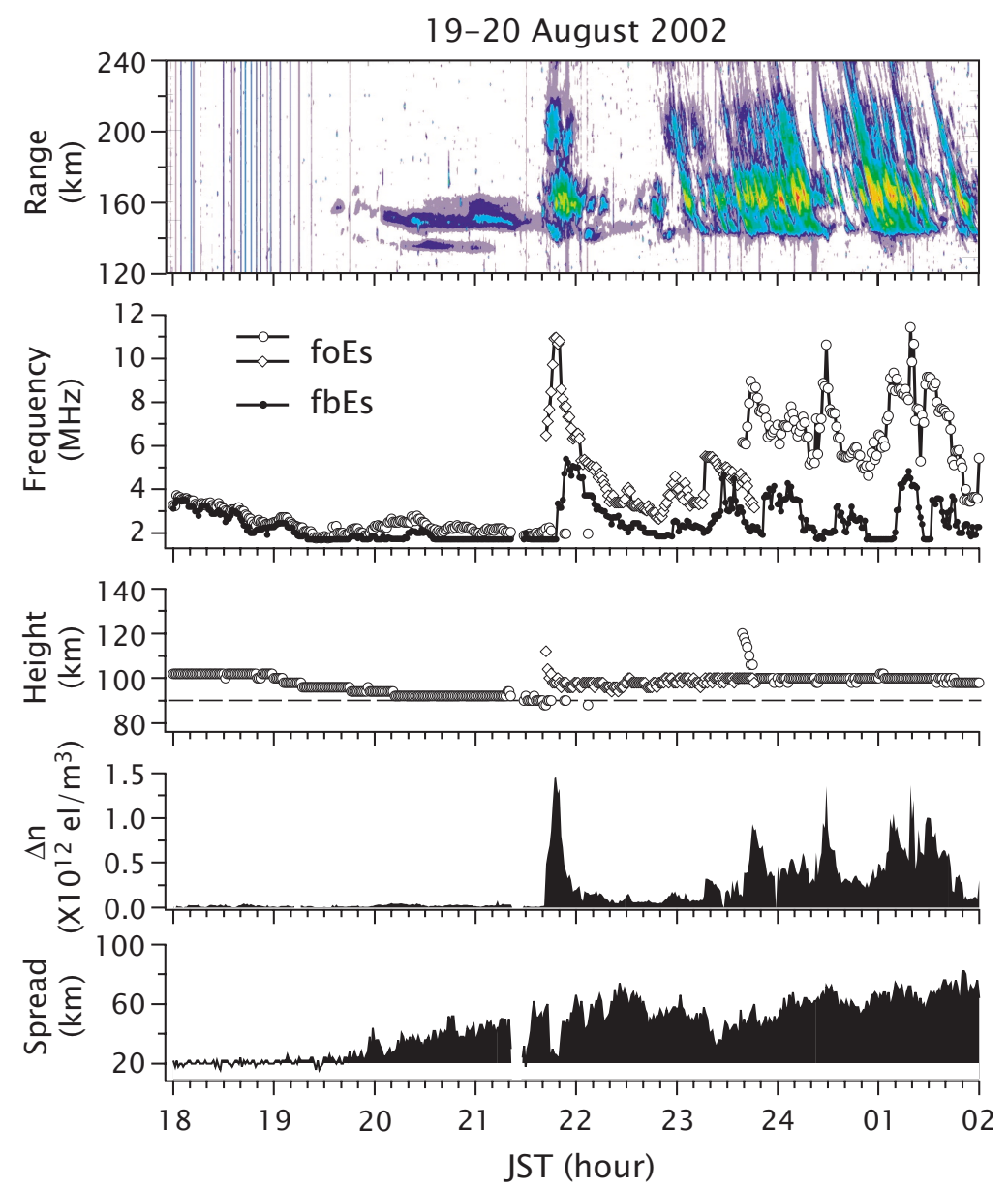

Fig. 6. Same as Fig. 3, but for the night of 19-20 August 2002. Both continuous and QP types of echoes were observed.

the horizontal axis covers $8 \mathrm{~h}$ with ionograms taken every 5 min. Radar echoes appeared before the E-region sunset (19:18 JST), unlike the previous events, with the echo power before sunset being somewhat weak. On this night, foEs and fbEs varied in a similar fashion throughout the time period under consideration, as shown in the second panel. Although there was some correlation between the radar echo power and foEs, for example, the peaks near 18:20, 19:30, and 22:15 JST, the overall agreement was not very good. Another difference from the earlier QP echo events was the layer height. Here the layer was located near $90 \mathrm{~km}$, as shown in the third panel, at least $10 \mathrm{~km}$ below typical QP echo altitudes.

The computed variability in $\Delta \mathrm{n}$ was not significant as compared to the one seen during QP echo events. A point to also note here is that $\Delta \mathrm{n}$ had a tendency to decrease with time, as did the range spread, although the echo power did not exhibit such a tendency until about 23:00 JST.

\subsection{9-20 August 2002}

Figure 6 shows the fourth event observed during the night of 19-20 August 2002. A special feature in the RTI plot is the appearance of two different backscatter layers. At 18:00 JST, the ionosonde observed a moderate blanketing-type sporadic E (second panel) centered at about $102 \mathrm{~km}$ (third panel), when no VHF echoes were detected. Next, foEs and fbEs gradually decreased while the layer descended in height with time. When the layer reached $96 \mathrm{~km}$ near 19:30 JST, weak continuous VHF echoes appeared, which intensified by the time the layer had descended to $94 \mathrm{~km}$. The continuous VHF echoes persisted until 21:40 JST when QP echoes started to appear, while the layer descended further down to about $90 \mathrm{~km}$. During the period from 20:00 to 21:30 JST, when the continuous echoes appeared, the sporadic E was weak and both foEs and fbEs remained fairly constant but there was still present a finite difference between foEs and fbEs. This behavior of sporadic E parameters was similar to that associated with the continuous echo event of 8-9 August (see Fig. 5).

As seen from Fig. 6, during the time when the QP echoes appeared, foEs and fbEs changed rather dynamically while the layer height remained fixed at about $100 \mathrm{~km}$ and $\Delta \mathrm{n}$ increased. These features were the same as for the QP echo events described previously. Obviously, the continuous echoes and the QP echoes were associated with sporadic 
E-layers having different properties and located at different heights. Note also that range spreading was higher during the QP relative to the continuous echoes.

\section{Discussion}

\subsection{Interpretation of Es parameters}

\subsubsection{Oblique reflection}

In the previous section, we presented $\Delta \mathrm{n}$ as a measure of electron density spatial inhomogeneity in the sporadic Elayer. For the computation of $\Delta \mathrm{n}$, we assumed that both foEs and fbEs were observed in the same volume of the sporadic E-layer. However, this is not always correct, because foEs may relate either to vertical or oblique reflections. The second echo trace seen at around 00:10 JST on 4 August (Fig. 3) could be such a case. After midnight, the foEs of the layer that persisted from the preceding hours (circles) gradually decreased, while its height remained constant. Concurrently, another sporadic E-layer (diamonds) with large foEs appeared at a higher altitude. This was faint when it first appeared at $120 \mathrm{~km}$ and the virtual height decreased at a constant rate. By about 00:20 JST, it eventually appeared to merge with the first layer near $100 \mathrm{~km}$. Similar rapidly descending layers were observed at 21:45 and 23:40 JST on 19 August (Fig. 6). These apparently descending layers were most probably due to an oblique reflection from a sporadic $\mathrm{E}$ that moved in the view, while blanketing of the F-layer was due to an overhead sporadic E-layer with smaller foEs. Such a situation could result in an overestimation of $\Delta \mathrm{n}$.

For most periods, except for the above cases, the layer height was fairly constant, which suggests that both foEs and fbEs were determined by the overhead layer, i.e. the scale size of plasma blobs may be smaller than the radius of a Fresnel zone (Whitehead, 1972), and the difference between the two parameters could indicate the measure of plasma inhomogeneity.

\subsubsection{Separation between the ionosonde and radar viewing volumes}

A disadvantage in this study is the separation between the ionosonde and the scattering volume of the VHF radar, since sporadic $\mathrm{E}$ varies not only temporally but also spatially. Nevertheless, a fairly good correlation between the radar echo and sporadic $\mathrm{E}$ parameters, especially $\Delta \mathrm{n}$, was obtained. This is not surprising if we consider that a comparison of the RTI plots for the Tanegashima South and North radars (see Fig. 1 for the locations) exhibited a temporal correlation with a small delay of about $10 \mathrm{~min}$ in the appearance of echoes (Saito et al., 2005).

Regarding the correlation between the ionosonde sporadic E parameters and the radar backscatter echoes, there may be two possible situations. If a cluster of sporadic $\mathrm{E}$ patches with meter-scale irregularities moved as an entity, there must be a time delay between the two observations. On the other hand, if the surrounding atmospheric conditions, which were responsible for the formation of sporadic E irregularities, varied with time over an area wider than the separation of the two viewing volumes, there must be no time difference between the two observations. Unfortunately, it was difficult to separate the two factors, and the results of a detailed comparison were chaotic. For example, on the night of 20-21 August (Fig. 4), a radar echo power peak at 22:35 JST correlated with the maximum foEs without a time offset, while the latter half of the echo event from 23:10 to 23:55 JST correlated well with the variation in the $\Delta \mathrm{n}$, with a 15 -min time delay. On the other hand, the maximum echo power at 23:30 JST coincided with the minimum fbEs. For a detailed comparison, including a common volume correlation analysis as in Hussey et al. (1998), the ionosonde should be located underneath the radar target.

\subsection{Comparison between radar echoes and Es parameters}

\subsubsection{Quasi-periodic echoes}

After the finding of QP echoes by Yamamoto et al. (1991), periodic height modulations of a thin sporadic E-sheet by gravity waves were proposed to explain their quasiperiodicity (Woodman et al., 1991). An experiment conducted in Kyushu, Japan (SEEK), however, could not confirm this hypothesis (Fukao et al., 1998). On the other hand, Hysell and Burcham (2000) and Maruyama et al. (2000) proposed a horizontally moving patchy structure, which yields the slanted pattern in RTI plots, although an origin of the periodicity was unexplained. Also, a patchy horizontal structure is preferable for the generation of the localized electric fields required for the plasma to become unstable (Haldoupis et al., 1996). In addition, a patchy structure results in large differences between the critical and blanketing frequencies. Maruyama et al. (2000) observed the coexistence of radar echoes and plasma blobs which caused a Fresnel diffraction of satellite radio waves, and showed that the difference in density between the surrounding sporadic $\mathrm{E}$ and the blobs did not contradict the ionosonde observations. Ogawa et al. (2002) found a good correlation between the MU radar backscatter and increases in foEs-fbEs in the ionograms obtained at the radar site, which is separated by $130 \mathrm{~km}$ from the radar scattering volume. On the other hand, Patra et al. (2005) found a rather poor correlation between coherent backscatter obtained with the Gadanki MST radar $\left(79.2^{\circ} \mathrm{E}, 13.5^{\circ} \mathrm{N}\right)$ and ftEs-fbEs obtained at Sriharikota $\left(80.1^{\circ} \mathrm{E}, 13.7^{\circ} \mathrm{N}\right)$ during the night. In their experiment, the separation between the ionosonde and radar backscattering volume was about $100 \mathrm{~km}$.

These horizontal plasma structures may be created by instability processes, wave activity, or other causes. The evolution of the structures, however, is not easy to observe directly or indirectly if only coherent backscatter radars are used, because they can only detect echo meter-scale irregularities there where the plasma becomes unstable. A rapid-run ionosonde can monitor the sporadic E-layer continuously, 
irrespective of the spatial inhomogeneity, patches and/or waves. Thus, changes in the ionogram parameters provide insight into what is happening at the onset of VHF radar backscattering.

Through the case studies shown in Figs. 3, 4, and 6, we obtained a general picture of sporadic E during QP echo occurrences. The development of spatial inhomogeneities, as evidenced by the difference between the electron densities corresponding to the foEs and fbEs, is necessary for the onset of QP echoes, which confirmed the results of Ogawa et al. (2002) at mid-latitudes, but did not agree well with the recent findings of Patra et al. (2005) at low latitudes. Tentatively, there seems to be a threshold level for foEs and $\Delta \mathrm{n}$, in order for the radar echoes to appear. When a radar echo was observed, foEs seemed to be higher than $6 \mathrm{MHz}$ and $\Delta \mathrm{n}$ was larger than $5 \times 10^{11} \mathrm{el} / \mathrm{m}^{3}$. Another finding here is that, on many occasions, the increase in foEs and decrease in fbEs was simultaneous.

Another parameter which signifies layer inhomogeneity is the range spread of Es trace. Hussey et al. (1998) found a correlation between the backscatter at $50-\mathrm{MHz}$ and the Es range spread using an ionosonde located underneath the radar target. Although their radar system could not generate RTI plots, and thus the echo characteristics were not categorized into QP or continuous types, it is worthwhile comparing the results. In all of the QP events analyzed here, the Es range spread was associated with the radar echo appearance, but its significance differed from event to event. On the night of 3-4 August 2002 (Fig. 3), around the period when the radar echo appeared, the Es spread and radar echo showed a relatively good overall correlation. However, the most intense spread on this night was seen between 21:10 and 21:50 JST with a very faint VHF radar echo. Although the radar target and ionosonde were $90 \mathrm{~km}$ apart, the spread and $\Delta \mathrm{n}$ were observed in the same volume of the sporadic E. Possibly the increase in $\Delta \mathrm{n}$ is more significant for the appearance of $\mathrm{QP}$ echoes than that of the amount of spread in the layer.

\subsubsection{Continuous echoes}

The radar echoes observed on the night of 8-9 August 2002 (Fig. 5), and during the short period before 21:35 JST on the night of 19-20 August (Fig. 6), exhibited the same characteristics as the continuous echoes reported previously by Yamamoto et al. (1991) and Ogawa et al. (1995). The height of the echoing regions was lower and the power was weaker than those of the well-developed QP echoes, which agrees with previous reports. The continuous echoes here are associated with the low-altitude sporadic E, a fact that was not confirmed in the previous experiments (Yamamoto et al., 1992; Ogawa et al., 1995, 2002). The Es parameters, however, had different characteristics than those relating to QP echoes. During the period when the continuous echoes appeared, both foEs and fbEs varied in a similar way, while the critical frequencies and $\Delta \mathrm{n}$ were not necessarily high. For example, in Fig. 5, the radar echo continued to be equally strong even when foEs and fbEs remained nearly the same at around 21:00 JST. Rather, the layer height seemed to be of importance for the appearance of continuous echoes. The ionosonde Es layer height was around $90 \mathrm{~km}$ when the continuous echo appeared, while it was around $100 \mathrm{~km}$ when the QP echo appeared. The importance of the layer height is more evident in Fig. 6. At first, the blanketing-type sporadic E-layer was at $102 \mathrm{~km}$, and gradually descended until it disappeared at about $90 \mathrm{~km}$. In this descending course, the continuous echo began gradually when the layer height reached $94 \mathrm{~km}$. The descent of a sporadic E-layer is well known and it relates to the downward phase progression of atmospheric tides in the lower thermosphere (Mathews and Bekeny, 1979)

\section{Conclusions}

We conducted simultaneous measurement of sporadic E-phenomena using a coherent VHF backscatter radar and a nearby ionosonde which were separated by about $90 \mathrm{~km}$ from the radar viewing volume. QP echoes were found to be associated with a spatially inhomogeneous Es plasma, which agreed with the findings of Ogawa et al. (2002). During the period when the QP echoes appeared, the enhanced spatial inhomogeneity was signified by increases in foEs and decreases in fbEs. The Es spreadness was also associated with the appearance of QP echoes, but its significance differed from event to event.

We found that continuous echoes were also associated with lower altitude sporadic E-layers, which is anticipated but it was not observed in previous studies. However, the relationship between the parameters for sporadic E and backscatter contrasted with that for QP echoes. Although a sporadic E-layer is required, the correlation between the backscatter power and foEs was not strong. In addition, spatial plasma structuring, as measured by foEs-fbEs, was of less importance, although an amount of Es spread seemed to be present.

Acknowledgements. The authors are grateful to $\mathrm{H}$. Kato and M. Nakamura for the operation of the ionosonde and data processing.

Topical Editor M. Pinnock thanks C. Haldoupis and P. Wilkinson for their help in evaluating this paper.

\section{References}

Bowman, G. G.: Quasi-periodic scintillations at mid-latitudes and their possible association with ionospheric sporadic-E structures, Ann. Geophys., 7, 259-268, 1989.

Fukao, S., Yamamoto, M., Tsunoda, R. T., Hayakawa, H., and Mukai, T.: The SEEK (Sporadic-E Experiment over Kyushu) campaign, Geophys. Res., Lett., 25, 1761-1764, 1998.

Haldoupis, C., Schlegel, K., and Farley, D. T.: An explanation for type 1 radar echoes from the midlatitude E-region ionosphere, Geophys. Res. Lett., 23, 97-100, 1996.

Hussey, G. C., Schlegel, K., and Haldoupis, C.: Simultaneous 50$\mathrm{MHz}$ coherent backscatter and digital ionosonde observations in the midlatitude E region, J. Geophys. Res., 103, 6991-7001, 1998. 
Hysell, D. L. and Burcham, J. D.: The 30-MHz radar interferometer studies of midlatitude E region irregularities, J. Geophys. Res., 105, 12 797-12 812, 2000.

Maruyama, T.: Shapes of irregularities in the sporadic E layer producing quasi-periodic scintillations, Radio Sci., 30, 581-590, 1995.

Maruyama, T., Fukao, S., and Yamamoto, M.: A possible mechanism for echo striation generation of radar backscatter from midlatitude sporadic E, Radio Sci., 35, 1155-1164, 2000.

Mathews, J. D. and Bekeny, F. S.: Upper atmosphere tides and the vertical motion of ionospheric sporadic layers at Arecibo, J. Geophys. Res., 84, 2743-2750, 1979.

Ogawa, T., Yamamoto, M., and Fukao, S.: Middle and upper atmosphere radar observations of turbulence and movement of midlatitude sporadic E irregularities, J. Geophys. Res., 100, 12 17312 188, 1995.

Ogawa, T., Takahashi, O., Otsuka, Y., Nozaki, K., Yamamoto, M., and Kita, K.: Simultaneous middle and upper atmosphere radar and ionospheric sounder observations of midlatitude E region irregularities and sporadic E layer, J. Geophys. Res., 107(A10), 1275, doi:10.1029/2001JA900176, 2002.

Patra, A. K., Sripathi, S., Rao, P. B., and Subbarao, K. S. V.: Simultaneous VHF radar backscatter and ionosonde observations of low-latitude E region, Ann. Geophys., 23, 773-779, 2005, SRef-ID: 1432-0576/ag/2005-23-773.

Saito, S., Yamamoto, M., Fukao, S., Marumoto, M., and Tsunoda, R. T.: Radar observations of field-aligned plasma irregularities in the SEEK-2 campaign, Ann. Geophys., 23, 2307-2318, 2005, SRef-ID: 1432-0576/ag/2005-23-2307.
Whitehead, J. D.: The structure of sporadic E from a radio experiment, Radio Sci., 7, 355-358, 1972.

Woodman, R. F., Yamamoto, M., and Fukao, S.: Gravity wave modulation of gradient drift instabilities in mid-latitude sporadic E irregularities, Geophys. Res. Lett., 18, 1197-1200, 1991.

Yamamoto, M., Fukao, S., Woodman, R. F., Ogawa, T., Tsuda, T., and Kato, S.: Mid-latitude E region field-aligned irregularities observed with the MU radar, J. Geophys. Res., 96, 1594315 949, 1991.

Yamamoto, M., Fukao, S., Ogawa, T., Tsuda, T., and Kato S.: A morphological study on mid-latitude E-region field-aligned irregularities observed with the MU radar, J. Atmos. Terr. Phys., 54, 769-777, 1992.

Yamamoto, M., Fukao, S., Tsunoda, R. T., Pfaff, R., and Hayakawa, H.: SEEK-2 (Sporadic-E Experiment over Kyushu 2) - Project outline, and significance, Ann. Geophys., 23, 2295-2305, 2005, SRef-ID: 1432-0576/ag/2005-23-2295.

Yokoyama, T., Yamamoto, M., and Fukao, S.: Computer simulation of polarization electric fields as a source of midlatitude field-aligned irregularities, J. Geophys. Res., 108(A2), 1054, doi:10.1029/2002JA009513, 2003.

Yokoyama, T., Yamamoto, M., Fukao, S., and Cosgrove, R. B.: Three-dimensional simulation on generation of polarization electric field in the midlatitude E-region ionosphere, J. Geophys. Res., 109, A01309, doi:10.1029/2003JA010238, 2004. 